Article

\title{
Effect of Slit Channel Width of a Shim Embedded in Slot-Die Head on High-Density Stripe Coating for OLEDs
}

\author{
Dongkyun Shin $\oplus^{\circ}$, Jinyoung Lee and Jongwoon Park* \\ School of Electrical, Electronics \& Communication Engineering, Korea University of Technology and Education, \\ Cheonan 330-708, Korea; speed21c@koreatech.ac.kr (D.S.); dlwlsdud9203@koreatech.ac.kr (J.L.) \\ * Correspondence: pjwup@koreatech.ac.kr
}

Received: 17 July 2020; Accepted: 6 August 2020; Published: 8 August 2020

check for updates

\begin{abstract}
With an attempt to achieve high-density fine organic stripes for potential applications in solution-processable organic light-emitting diodes (OLEDs), we have performed slot-die coatings using a shim with slit channels in various shapes (rectangular-shaped narrow, rectangular-shaped wide, and reversely tapered channels) in the presence of narrow $\mu$-tips. Based on hydraulic-electric circuit analogy, we have analyzed the fluid dynamics of an aqueous poly (3,4-ethylenedioxythiophene): poly (4-styrenesulfonate) (PEDOT:PSS). It is observed that the coating speed can be increased and the stripe width can be reduced using a shim with rectangular-shaped wide slit channels. It is attributed that the hydraulic resistance is decreased and thus more fluid can reach a substrate through $\mu$-tips. This behavior is consistent with the simulation result of the equivalent electrical circuit with a DC voltage source representing a pressure source. Using the shim with $150-\mu \mathrm{m}$-wide slit channels, we have successfully fabricated 200 PEDOT:PSS stripes within the effective coating width $(150 \mathrm{~mm})$ and 160 OLED stripes (34 stripes per inch) with the luminance of $325 \mathrm{~cd} / \mathrm{m}^{2}$ at $5 \mathrm{~V}$.
\end{abstract}

Keywords: slot-die head; stripe coating; electronic-hydraulic analogy; hydraulic resistance; OLEDs

\section{Introduction}

Due to a simple process, low material loss, and scalability to large-area manufacturing, printing and coating processes have attracted much attention for the fabrication of organic light-emitting diode (OLED) display panels [1,2], OLED lightings [3-5], solar cells [6,7], sensors [8,9], batteries [10,11], etc. Printing processes (e.g., inkjet [12,13], gravure [14,15], nozzle [16,17], etc.) have been employed to fabricate the emission layers of OLEDs, which require fine patterning. Meanwhile, coating processes (e.g., blade, spin, spray, slot, etc.) have been utilized to fabricate the blanket (common) layers of OLEDs, which require large-area uniform films [3,5]. The printing process has a big advantage, in that fine and accurate patterning in the web and cross-web directions is readily available. However, it has the disadvantage that it is difficult to maintain the equipment and print high-viscosity solutions [18]. The coating process has the opposite characteristics to the printing process. It enables coating of a wide range of process materials (low- and high-viscosity solutions). Of those, blade coating is preferred for processing of large areas with no pattern [19-21]. Although spin coating provides very uniform organic thin films, its scalability is limited [22,23]. Spray coating has a high roll-to-roll (R2R) compatibility, but requires a mask for patterning, thereby degrading edge resolution [24-26]. As a premetered method, slot-die coating is compatible with both R2R and sheet-to-sheet deposition processes [27,28]. It enables simultaneous multilayer formation, yielding a discrete bilayer film [29]. The main process parameters that determined the thickness and width of a patterned stripe in the R2R slot-die coating system were the coating speed, flow rate, and coating gap [30]. Of those, the coating speed had the most influence on 
stripe profiles. Unlike other coating methods, slot-die coating can provide patterning in the transverse (cross-web) direction (i.e., stripe coating) and in the longitudinal (web) direction (i.e., intermittent coating) [31]. Inkjet printing requires a bank structure to confine ink droplets within pixels. However, such a bank structure is unnecessary if stripe coating is feasible [32-34]. Although inkjet printing enables fine stripe coating, the printed line shows various behaviors; individual drops, scalloped, uniform, bulging, and stacked coins, depending on the drop spacing [34].

For stripe coating using slot-die coating, a slot-die head with a shim and a meniscus guide is required. The shim mask is embedded into the head to define the feed slot width. Depending on the shim configuration, the die-outlet velocity, which affected the edge profiles of the wide stripe-patterned film, was shown to be controlled [35]. The meniscus guide is protruded from the head lip in order to control the meniscus [36]. Such a meniscus guide together with a shim was first employed to fabricate wide stripes having a centimeter width required for solar cells $[37,38]$. We explored this scheme in OLEDs and demonstrated that thin-film stripes of poly (3,4-ethylenedioxythiophene): poly (4-styrenesulfonate) (PEDOT:PSS) having a micrometer width could be fabricated by the slot-die head with protruded $\mu$-tips [39-41]. Using the shim with a thickness of $25 \mu \mathrm{m}$ and the $\mu$-tips with a width of $150 \mu \mathrm{m}$ and a length of $250 \mu \mathrm{m}, 100$ PEDOT:PSS stripes were fabricated without coating defects (line break) over the active width of $150 \mathrm{~mm}$ [39]. The number of coated stripes was increased to 150 by reducing the $\mu$-tip length to $150 \mu \mathrm{m}$ [40]. The coated PEDOT:PSS stripes exhibited an average width of $168 \mu \mathrm{m}$ and an average thickness of $103 \mathrm{~nm}$ at $20 \mathrm{~mm} / \mathrm{s}$ using the $\mu$-tips with a width of $150 \mu \mathrm{m}$. To increase the stripe density further, we investigated the effect of the $\mu$-tip configuration on the stripe profiles. Using the tapered $\mu$-tips having a length of $100 \mu \mathrm{m}$, we successfully fabricated 175 stripes with the average width of $62 \mu \mathrm{m}$ and thickness of $113 \mathrm{~nm}$ at $44 \mathrm{~mm} / \mathrm{s}$ [41]. It was addressed that the tapered $\mu$-tip suppressed both line break occurred at low coating speeds and line broadening appeared with the wide $\mu$-tip. It was also demonstrated that the stripe density could be doubled using a slot-die head with two meniscus guides embedded, each of which had 175 linearly tapered $\mu$-tips. For practical applications in large-area OLEDs, however, the stripe density should be boosted further.

To this end, we first need to analyze the fluid dynamics in slot-die head with a cavity, slit channels, and $\mu$-tips. It can be done by computational fluid dynamics (CFD) simulation [42]. The 2D finite element method was developed for slot-coating flow [43]. A coating window for the low-flow limit regime was analyzed using CFD simulations [28,44]. In [45], 3D flow simulations were performed to analyze saw-tooth meniscus shape. Furthermore, a novel tracking method was developed to investigate the vortex-free coating windows for slot-die coating [46]. However, CFD method requires specialized and costly software and lots of computational efforts to simulate the fluid dynamics in the slot-die head with a number of $\mu$-tips. A simple and useful method is to use the relationship between the hydraulic (Hagen-Poiseuille's law) and electrical circuit (Ohm's law). The pressure drop appearing in fluid channels can be represented by the voltage drop in the circuit. Similarly, the fluid flowing through the channels corresponds to the current flowing in the circuit and the hydraulic resistance affecting the fluid flow to the electrical resistance [47,48]. This analogy is valid when the flow is laminar, viscous, and incompressible. Even so, the use of a hydraulic-electric circuit analogy is useful in designing a complex microfluidic slot-die coating system with a large number of 1D-like microchannels (closed slit channels and open $\mu$-tip channels). From the electronic-hydraulic analogy, it is expected that a wide slit channel might deliver more fluid to a substrate, a feature demanded for multiple stripe coating. To verify it by experiment, we have first investigated the effect of the slit channel configuration (rectangular-shaped narrow, rectangular-shaped wide, and reversely tapered channels) on the coating behaviors in the presence of a narrow $\mu$-tip. It is addressed that the coating speed can be increased and the stripe width can be reduced using a shim with a rectangular-shaped wide slit channel. To obtain high-density fine organic stripes, we have then employed the slot-die head with wide slit channels where narrow $\mu$-tips are deployed and successfully fabricated 200 PEDOT:PSS stripes and 160 OLED stripes with the luminance of $325 \mathrm{~cd} / \mathrm{m}^{2}$ at $5 \mathrm{~V}$. 


\section{Methods}

\subsection{Simulation}

Presented in Figure 1 is the schematic view of slot-die head with multiple $\mu$-tips and its equivalent electrical circuit. The inlet is connected with an external syringe pump. A liquid provided by the syringe pump fills the cavity (ink distribution chamber or reservoir) and then flows through the slit channels formed by a shim. A liquid coming out of the slit channels flows along the head lip due to lateral capillary force and along the $\mu$-tips. Other than microfluidics [47], there exist both closed and open-channel flows in slot-die head. It implies that there are two forces of gravity and pressure along the flow direction. The hydraulic pressure is the main driving force in the cavity and slit channels, whereas the component of gravity (atmospheric pressure) is the driving force along the head lip and the $\mu$-tip. It is noted that those two forces are mixed and not independent in slot-die head. In open-channel flow, the flow resistance is determined by the four components; skin friction induced by surface roughness, form resistance by separation of flow, wave resistance by distortion of the free surface, and flow unsteadiness by flow acceleration or deceleration [49]. Of those, form resistance and flow unsteadiness are dominant in slot-die head. In a transient state, the separation of flow occurs at the fork of the die lip and the $\mu$-tip. Flow unsteadiness occurs between the $\mu$-tip and the substrate (i.e., coating gap). In Figure 1, the resistance to fluid flow (hydraulic resistance) through the cavity, through the slit channels, along the head lip, and along the $\mu$-tip is represented by $R_{\mathrm{C}}, R_{\mathrm{S}}, R_{\mathrm{L}}$, and $R_{\mathrm{T}}$, respectively. The hydraulic resistance in the closed channels can be evaluated by Poiseuille's law [50,51], which is written as

$$
R=C_{\text {geometry }} \eta \frac{L}{A^{2}}
$$

where $C_{\text {geometry }}$ denotes a geometry coefficient, $\eta$ the viscosity of a fluid, $L$ the length of channel, and $A$ the cross-sectional area of the channel. Hagen-Poiseuille's law can only be used for channels that are perfectly straight and infinitely long. Meanwhile, no standard equation for the hydraulic resistance along the head lip and $\mu$-tips (in open-channel flow) is available.

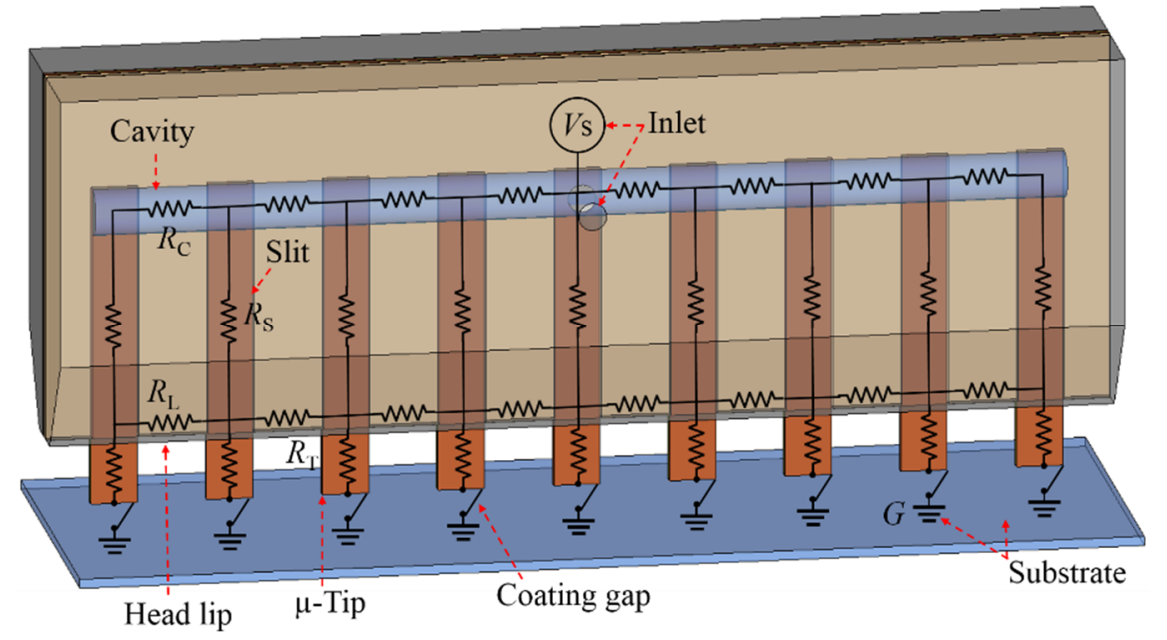

Figure 1. Schematic view of slot-die head with multiple $\mu$-tips and its equivalent electrical circuit.

Shown in Figure 2a is the pressure source with a syringe pump and its equivalent circuit symbol, and displayed in Figure $2 b$ is the circuit layout with a DC voltage source for simulations. In pressure-driven microfluidic devices, the pressure drop across the inlet and outlet of a device is not affected by the externally connected syringe pump. In this case, the syringe pump corresponds to an independent DC current source [47]. In slot-die head, however, the syringe pump is an independent constant pressure source and thus analogous to an independent DC voltage source because there exists a reservoir (i.e., cavity) (Figure 2a). A pressurized reservoir (cavity) connected with the syringe pump 
provides pressure to each slit. Even after the syringe pump is stopped, therefore, a fluid still flows out of slit channels due to the internal pressure existing inside the cavity and slit channels. A circuit simulator (Proteus 8.0 ver) was used to validate the correlations of flow rate to current and hydraulic resistance to electrical resistance. For a straightforward comparison, the value of the electrical resistance was taken as ratios and not as absolute values.

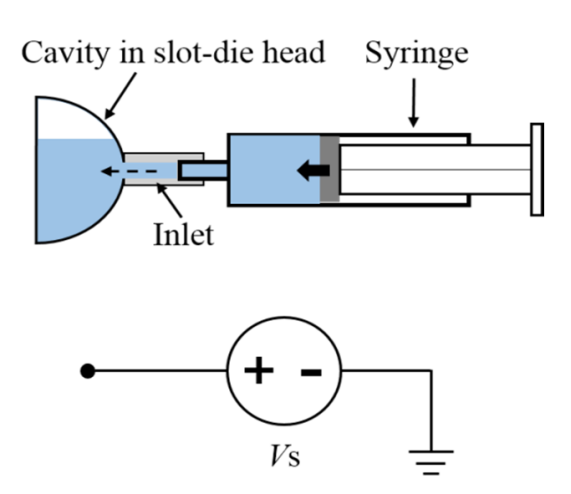

(a)

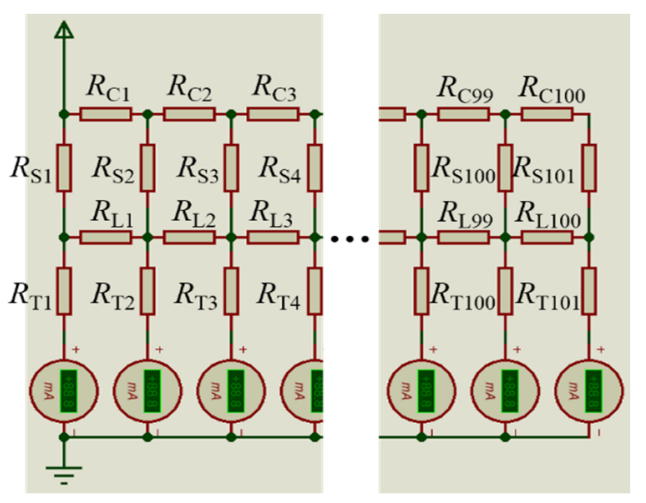

(b)

Figure 2. (a) A pressure source with a syringe pump and its equivalent circuit symbol; (b) circuit layout with a DC voltage source for simulations (half of the slot head is considered due to its symmetric configuration).

\subsection{Experiment}

To fabricate fine organic thin-film stripes, we used a R2R slot coating system [39]. It is composed of a holder for a slot-die head having a length of $200 \mathrm{~mm}$, width of $40 \mathrm{~mm}$, and height of $58 \mathrm{~mm}$, pre-drying unit in vacuum (pressure up to $5 \times 10^{-4}$ Torr), the web controller for web speeds ranging from 0.1 to $100 \mathrm{~mm} / \mathrm{s}$, the externally connected syringe pump with flow rates in the range from 0.18 to $159.8 \mathrm{~mL} / \mathrm{min}$ (11 Elite I/W Single, Harvard Apparatus), $\mathrm{O}_{3}$ plasma treatment with the maximum power of $0.3 \mathrm{~kW}$, and ionizers for removing dusts. The semicircular cavity in the slot-die head has the length of $156 \mathrm{~mm}$ and the radius of $1 \mathrm{~mm}$. Shown in Figure 3 are the schematic view of a meniscus guide and a shim superimposed. For the experiment, the $\mu$-tip width was fixed to $50 \mu \mathrm{m}$. The slit channel length was also fixed to $12.7 \mathrm{~mm}$. We fabricated three different shapes of slit channels; a rectangular-shaped

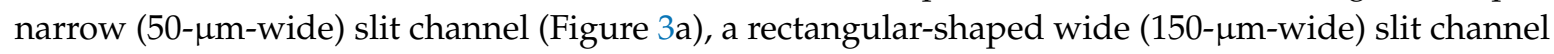
(Figure 3b), and a reversely tapered slit channel (Figure 3c). In the reversely tapered slit channel, the slit width was increased from 50 to $150 \mu \mathrm{m}$. Both the meniscus guide with $\mu$-tips and the shim were fabricated by a laser cutter using a plastic film. A plastic film rather than a stainless steel film was used to facilitate the laser processing of $\mu$-tips. Using a polyethylene terephthalate (PET) film, however, the $\mu$-tip became ill-defined (rounded) due to laser heat when it was machined to a width of $50 \mu \mathrm{m}$ (Figure 4a). The PET film was suitable for making the $\mu$-tip with a width of $80 \mu \mathrm{m}$ or more. To fabricate narrower $\mu$-tips, we employed a polyimide (PI) film with high heat resistance. As evident in Figure $4 \mathrm{~b}$, we obtained the $\mu$-tip with sharp corners. When it was machined to a width below $50 \mu \mathrm{m}$, however, heat-induced deformation (tip bending and nonuniformity in tip width) of the $\mu$-tip occurred (Figure 4c). Therefore, the minimum slit channel width was determined to be $50 \mu \mathrm{m}$. The coating gap was fixed to $20 \mu \mathrm{m}$. The meniscus guide was thick $(=175 \mu \mathrm{m})$ enough to prevent tip bending and the thickness of the shim we used was $25 \mu \mathrm{m}$ [41]. Each slit channel has the cross-sectional area $(A)$ equal to the slit channel width $\times$ shim thickness. We used a PET film roll having a width of $170 \mathrm{~mm}$ as a flexible substrate and an aqueous PEDOT:PSS (Clevios AI 4083) as a coating solution. The active coating width on the film roll was $150 \mathrm{~mm}$. Because the surface tension of the pristine PEDOT:PSS solution was high, it was difficult to perform uniform slot coating. To enhance its wettability on the substrate, a fluorosurfactant $(0.2 \mathrm{wt} . \%)$ was added into the pristine solution as a wetting agent [39]. An area scan camera (acA1300-30gm, BASLER, Ahrensburg, Germany) was installed on the coating 
system to measure the fluid distribution. The coated PEDOT:PSS films were dried in the pre-drying unit (in vacuum) for $10 \mathrm{~min}$ and the hard-baking was done on a hot plate at $80^{\circ} \mathrm{C}$ for $20 \mathrm{~min}$. The width and thickness of coated stripes were measured using a 3D optical surface profiler (NV 6300, ZYGO, Middlefield, CT, USA) [39].

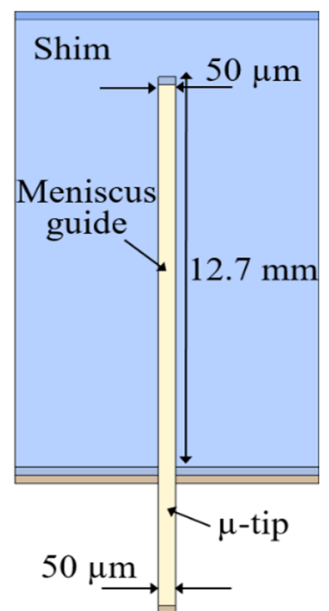

(a)

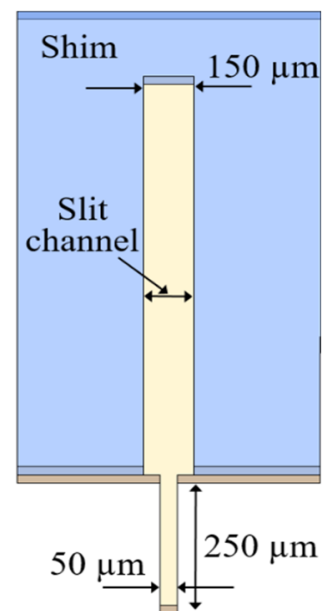

(b)

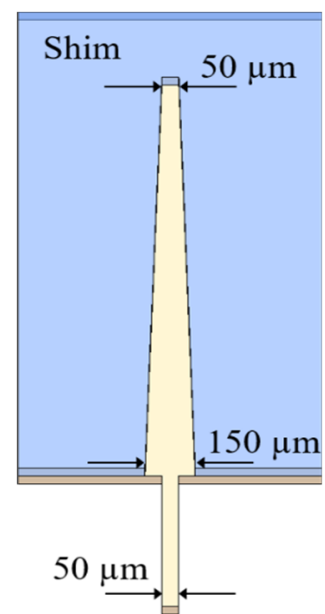

(c)

Figure 3. Schematic view of a meniscus guide with $50-\mu \mathrm{m}$-wide and $250-\mu \mathrm{m}$-long $\mu$-tip and a shim with the silt channel width of (a) $50 \mu \mathrm{m}$; (b) $150 \mu \mathrm{m}$; and (c) the reversely tapered slit channel.

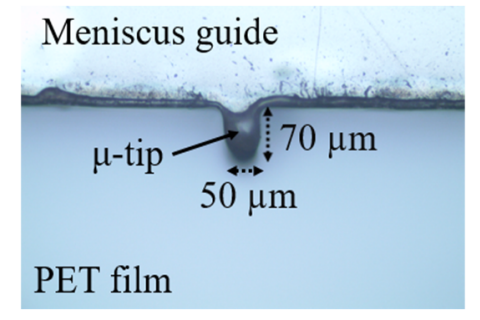

(a)

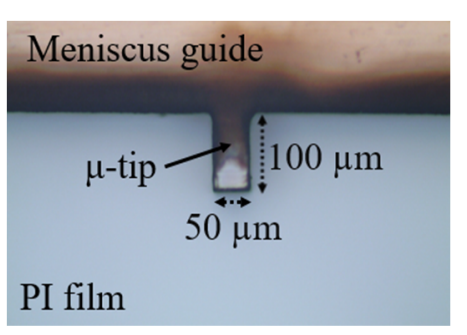

(b)

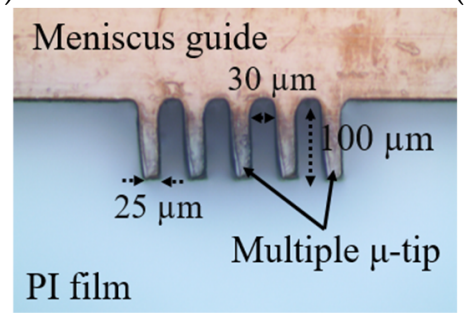

(c)

Figure 4. Optical images of a single $\mu$-tip fabricated by a laser cutter using (a) polyethylene terephthalate (PET) film; (b) polyimide (PI) film; and (c) multiple $\mu$-tips processed to a width of $30 \mu \mathrm{m}$.

\section{Results and Discussion}

\subsection{Single Line Coating}

In order to study the effect of the slit channel configuration on the fluid dynamics and thin-film properties, we first performed single stripe coatings. Figure 5 shows the measured optical images and profiles of a single PEDOT:PSS stripe coated at a coating speed of $10 \mathrm{~mm} / \mathrm{s}$. The measured width and thickness values for different coating speeds are summarized in Table 1. For single stripe coating, the flow rate was $1 \mu \mathrm{l} / \mathrm{min}$. At the same coating speed $(10 \mathrm{~mm} / \mathrm{s})$, the wide $(150-\mu \mathrm{m}$-wide) slit channel provided the widest and thickest stripe, followed by the reversely tapered channel and then the narrow (50- $\mu \mathrm{m}$-wide) slit channel. It is attributed that the hydraulic resistance is decreased and thus more 
fluid reaches the substrate with increasing cross-sectional area $(A)$ of slit channel or longitudinal area (slit channel width $\times$ slit channel length). The effect of the slit channel configuration on the fluid flow can be seen by measuring the fluid distribution near the $\mu$-tip at a fixed coating speed of $10 \mathrm{~mm} / \mathrm{s}$ (Figure 6). The fluid dynamics was compared in terms of the distance $\left(D_{\mathrm{L}}\right)$ the PEDOT:PSS solution spread out from the $\mu$-tip and the smallest width $\left(W_{M}\right)$ of the fluid stream formed near the $\mu$-tip end. At $10 \mathrm{~mm} / \mathrm{s}$, the measured $D_{\mathrm{L}}$ value using the $50-\mu \mathrm{m}$-wide slit channel (Figure $6 \mathrm{a}$ ), the $150-\mu \mathrm{m}$-wide slit channel (Figure 6b), and the reversely tapered slit channel (Figure 6c) was about 206, 218, and $212 \mu \mathrm{m}$, respectively. Namely, the $D_{\mathrm{L}}$ value increases with increasing cross-sectional area $(A)$ of slit channel or longitudinal area. It implies that more fluid is distributed along the die lip because more fluid flows out of the wide $\left(150-\mu \mathrm{m}\right.$-wide) slit channel. Therefore, the largest $W_{\mathrm{M}}$ value $(100 \mu \mathrm{m})$ was obtained using the wide slit channel, indicating that more fluid reached the substrate.

Table 1. Summary of measured width $(W)$ and thickness $(T)$ of those poly (3,4-ethylenedioxythiophene): poly (4-styrenesulfonate) (PEDOT:PSS) stripes for different coating speeds $(V)$.

\begin{tabular}{|c|c|c|c|c|c|c|}
\hline \multirow{2}{*}{$\begin{array}{l}\text { Coating } \\
\text { Speed }\end{array}$} & \multicolumn{2}{|c|}{$50-\mu \mathrm{m}-$ Wide Slit Channel } & \multicolumn{2}{|c|}{ 150- $\mu \mathrm{m}$-Wide Slit Channel } & \multicolumn{2}{|c|}{$\begin{array}{c}\text { Reversely Tapered Slit } \\
\text { Channel }\end{array}$} \\
\hline & $W(\mu \mathrm{m})$ & $T(\mathrm{~nm})$ & $W(\mu \mathrm{m})$ & $T(\mathrm{~nm})$ & $W(\mu \mathrm{m})$ & $T(\mathrm{~nm})$ \\
\hline 10 & $131 \pm 2$ & $113 \pm 3$ & $151 \pm 2$ & $139 \pm 3$ & $145 \pm 2$ & $131 \pm 4$ \\
\hline 13 & $112 \pm 2$ & $105 \pm 2$ & $130 \pm 1$ & $130 \pm 2$ & $126 \pm 2$ & $124 \pm 2$ \\
\hline 16 & $102 \pm 2$ & $90 \pm 2$ & $117 \pm 2$ & $125 \pm 3$ & $112 \pm 1$ & $118 \pm 2$ \\
\hline 20 & \multirow{2}{*}{\multicolumn{2}{|c|}{ Line breakup }} & $103 \pm 2$ & $118 \pm 3$ & $100 \pm 2$ & $108 \pm 5$ \\
\hline 25 & & & $90 \pm 2$ & $105 \pm 4$ & \multicolumn{2}{|c|}{ Line breakup } \\
\hline
\end{tabular}

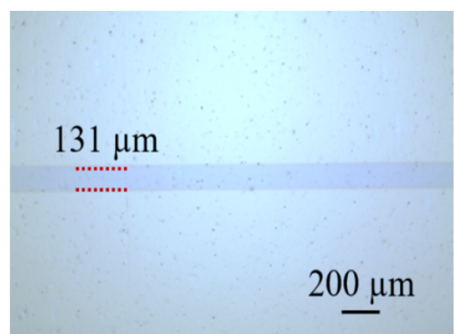

(a)

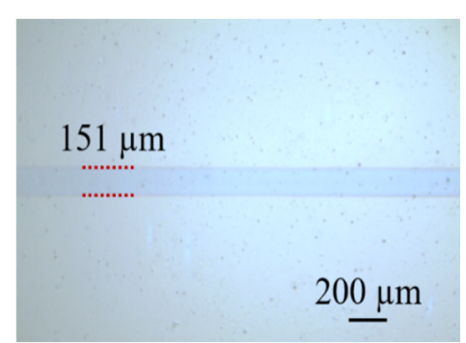

(b)

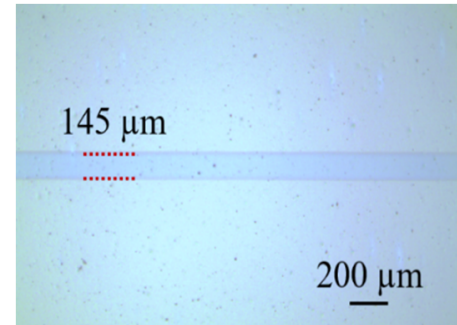

(c)

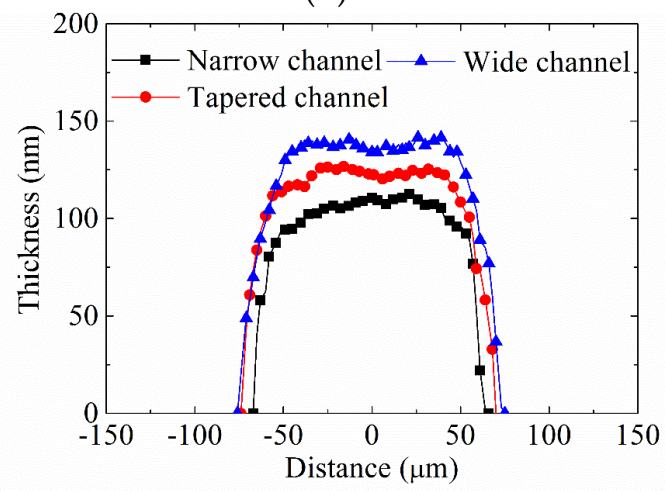

(d)

Figure 5. Optical images of a single PEDOT:PSS stripe coated at $10 \mathrm{~mm} / \mathrm{s}$ using a (a) $50-\mu \mathrm{m}$-wide slit channel, (b) 150- $\mu \mathrm{m}$-wide slit channel, and (c) reversely tapered slit channel; (d) measured profiles of those stripes. 


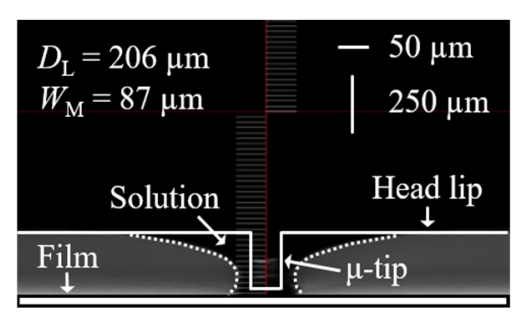

(a)

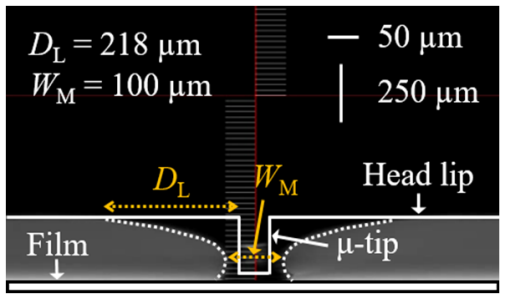

(b)

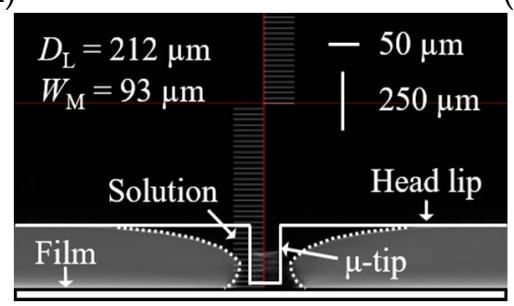

(c)

Figure 6. Measured fluid distribution near the $\mu$-tip during stripe coating at $10 \mathrm{~mm} / \mathrm{s}$ using the (a) 50- $\mu \mathrm{m}$-wide slit channel, (b) 150- $\mu \mathrm{m}$-wide slit channel, and (c) reversely tapered slit channel.

Presented in Figure 7 are the measured optical images of a single PEDOT:PSS stripe coated using those shims at a maximum coating speed $\left(V_{\mathrm{M}}\right)$. It is obvious from Figure 7 and Table 1 that we can obtain the finest stripe at a maximum coating velocity as the stripe width and thickness decrease with increasing coating velocity. The maximum coating velocity was $16 \mathrm{~mm} / \mathrm{s}$ with the $50-\mu \mathrm{m}$-wide slit channel. However, it was increased to $20 \mathrm{~mm} / \mathrm{s}$ using the reversely tapered slit channel and up to $25 \mathrm{~mm} / \mathrm{s}$ using the $150-\mu \mathrm{m}$-wide slit channel. At the maximum coating speed, we achieved the narrowest $(90 \mu \mathrm{m})$ and thinnest $(105 \mathrm{~nm})$ stripe using the $150-\mu \mathrm{m}$-wide slit channel.

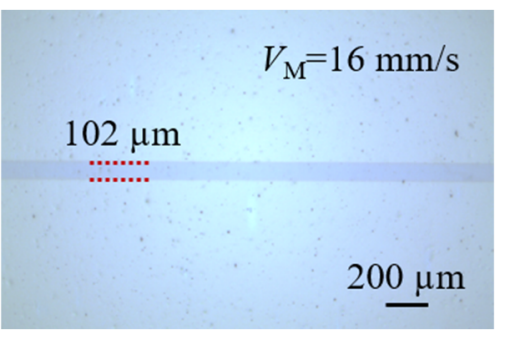

(a)

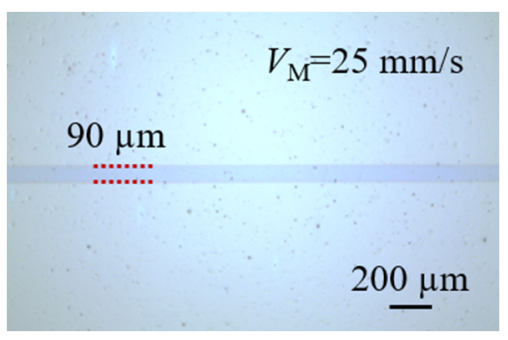

(b)

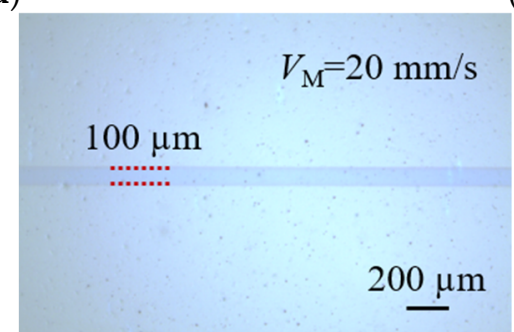

(c)

Figure 7. Measured optical images of a single PEDOT:PSS stripe coated using the (a) $50-\mu \mathrm{m}$-wide slit channel at the maximum coating speed $\left(V_{\mathrm{M}}\right)$ of $16 \mathrm{~mm} / \mathrm{s},(\mathbf{b}) 150-\mu \mathrm{m}$-wide slit channel at $25 \mathrm{~mm} / \mathrm{s}$, and (c) reversely tapered slit channel at $20 \mathrm{~mm} / \mathrm{s}$.

Figure 8 shows the fluid distribution near the $\mu$-tip measured at the maximum velocity. It was observed that both $D_{\mathrm{L}}$ and $W_{\mathrm{M}}$ values were reduced at a maximum coating speed, compared with the fluid distribution at $10 \mathrm{~mm} / \mathrm{s}$ (Figure 6). Therefore, the effective amount of solution per unit area discharged from the channel decreases as the coating speed increases. It results in a decrease in the stripe width and thickness with increasing coating speed. With the $150-\mu \mathrm{m}$-wide slit channel, the $D_{\mathrm{L}}$ 
value was reduced from 218 to $170 \mu \mathrm{m}$ and the $W_{M}$ value $(=62 \mu \mathrm{m})$ was getting close to the $\mu$-tip width. Above the maximum coating speed, the $W_{M}$ value is smaller than the $\mu$-tip width and eventually line breakup (defect) occurs. It is apparent that such a wide slit channel enables us to increase the maximum coating speed because more fluid reaches the substrate. We will return to this point later with the circuit simulation results.

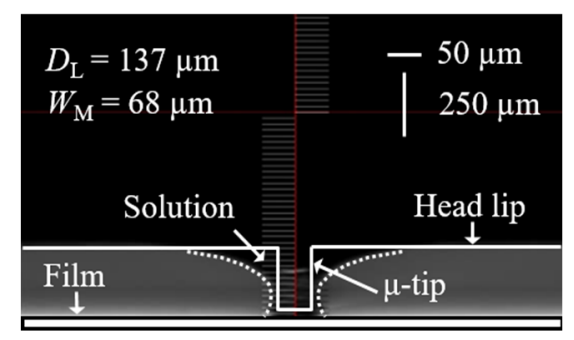

(a)

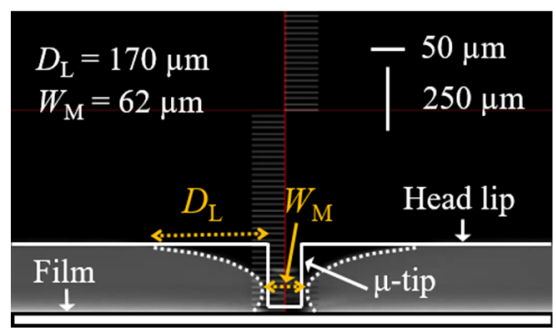

(b)

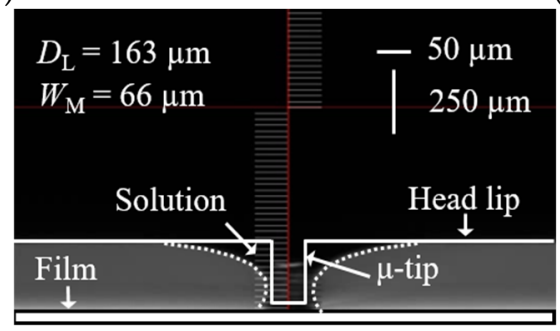

(c)

Figure 8. Measured fluid distribution near the $\mu$-tip during stripe coating using the (a) 50 - $\mu \mathrm{m}$-wide slit channel at the maximum coating speed of $16 \mathrm{~mm} / \mathrm{s}$, (b) $150-\mu \mathrm{m}$-wide slit channel at $25 \mathrm{~mm} / \mathrm{s}$, and (c) reversely tapered slit channel at $20 \mathrm{~mm} / \mathrm{s}$.

\subsection{High-Density Line Coating}

To demonstrate such a positive effect of the wide slit channel in multiple stripe coatings, we fabricated 200 PEDOT:PSS stripes using the shim with wide (150- $\mu \mathrm{m}$-wide) slit channels (Figure 9). The total number of $\mu$-tips with the width of $50 \mu \mathrm{m}$ was 200 and they were placed $700 \mu \mathrm{m}$ apart. For comparison, we also fabricated them using the shim with narrow (50- $\mu \mathrm{m}$-wide) slit channels. For multiple stripe coating, the flow rate was increased to $200 \mu \mathrm{L} / \mathrm{min}(200 \times 1 \mu \mathrm{L} / \mathrm{min})$ in proportion to the number of $\mu$-tips [30]. In the presence of $250-\mu m$-long $\mu$-tips, it was not feasible to fabricate 200 stripes using the shim with narrow (50- $\mu$ m-wide) slit channels. It was because the solutions from the neighboring outlets (slit channels) were merged on the die lip before reaching a stable coating mode. It was avoidable by increasing the coating velocity. When the $\mu$-tip was long, however, line break occurred easily and randomly in several $\mu$-tips [39]. To study its effect on fluid flow, we performed the circuit simulations by varying the $R_{\mathrm{T}}$ value in Figure $2 \mathrm{~b}$. In the circuit, the $R_{\mathrm{S}}$ value for the rectangular-shaped narrow (50- $\mu \mathrm{m}$-wide) slit channel was assumed to be $1 \mathrm{k} \Omega$. As the hydraulic resistance is inversely proportional to the slit channel width, the $R_{\mathrm{S}}$ value for the wide $(150-\mu \mathrm{m}$-wide) slit channel was assumed to be $333 \Omega$. Because no standard equation for $R_{\mathrm{T}}$ was available, it was assumed to be $1 \mathrm{k} \Omega$ for the 250 - $\mu \mathrm{m}$-long $\mu$-tip. Similarly, $R_{\mathrm{T}}$ was assumed to be $400 \Omega$ for $100-\mu \mathrm{m}$-long $\mu$-tip, considering the hydraulic resistance is proportional to the channel (tip) length. Once the meniscus can bridge the gap difference between the $\mu$-tip and substrate, no fluid flows along the head lip. Therefore, the $R_{\mathrm{L}}$ value $\left(10 \mathrm{k} \Omega\right.$ ) is much higher than the $R_{\mathrm{T}}$ value. From Equation (1), the $R_{\mathrm{C}}$ value per unit length of $700 \mu \mathrm{m}$ was calculated to be $0.04 \mathrm{~m} \Omega$ when $R_{\mathrm{S}}=1 \mathrm{k} \Omega$ (hydraulic resistance $\propto 1 / A^{2}$ ). For the simulation, we applied $10 \mathrm{DC}$ voltage in the circuit. When the $R_{\mathrm{T}}$ value was reduced from 1 to $400 \Omega$ (a decrease by a factor of 2.5), the current was increased from 5 to $7.13 \mathrm{~mA}$. It implies that the volumetric flow rate increases and thus more fluid reaches the substrate. It is because, just as all wires have resistance to current, the $\mu$-tip has resistance to fluid flow (electronic-hydraulic analogy). Based on the simulation result, we reduced the $\mu$-tip length from 250 to $100 \mu \mathrm{m}$ (a decrease by a 
factor of 2.5) and performed multiple stripe coating. Although such a problem (line breakup before separation) was suppressed, coating 200 stripes without defects still failed using the shim with narrow (50- $\mu \mathrm{m}$-wide) slit channels.

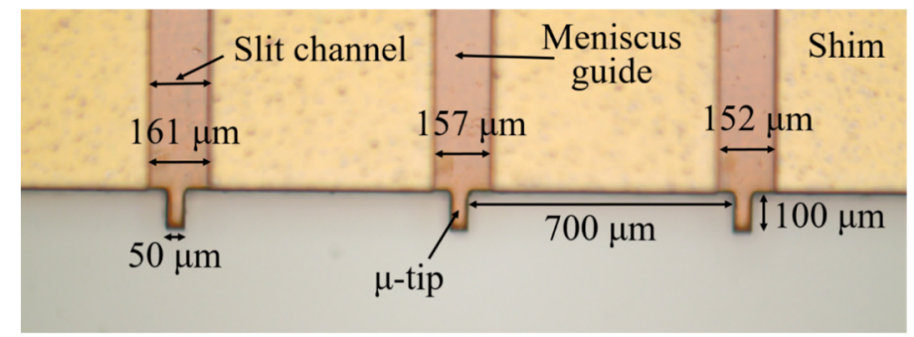

Figure 9. Optical image of a meniscus guide with $50-\mu \mathrm{m}$-wide and $100-\mu \mathrm{m}$-long $\mu$-tips and a shim with 150- $\mu \mathrm{m}$-wide slit channels for the coating of high-density PEDOT:PSS stripes (200 lines).

Meanwhile, when line breakup occurred at one $\mu$-tip, the coated stripes next to it became wide and thick, as evident in Figure 10 showing the optical image of PEDOT:PSS stripes coated using the shim with $50-\mu \mathrm{m}$-wide slit channels. The width of the coated stripes lay within the range between 94 and $110 \mu \mathrm{m}$. However, the width of the coated stripes next to the broken line was increased to $120-124 \mu \mathrm{m}$. This phenomenon can be captured by the circuit simulation in Figure $2 \mathrm{~b}$. When one of the channels was open, the current flowing through the channels next to it was increased from 5 to $5.2 \mathrm{~mA}$. It implies that more fluid flows through its adjacent channels, resulting in an increase of stripe width and thickness.

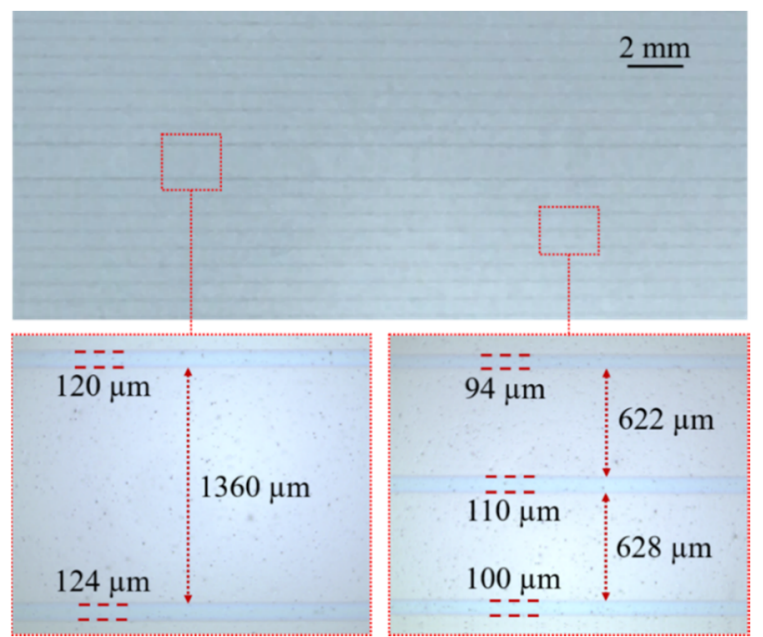

Figure 10. Image of multiple PEDOT:PSS stripes coated using the shim with 50- $\mu$ m-wide slit channels at $27 \mathrm{~mm} / \mathrm{s}$.

We then investigated the effect of $R_{\mathrm{S}}$ on multiple stripe coatings. From the circuit simulation, it was observed that the current flowing through the $\mu$-tip increased from 5 to $7.52 \mathrm{~mA}$ when the $R_{\mathrm{S}}$ value decreased from 1 to $333 \Omega$ (a decrease by a factor of 3 ). Therefore, it is expected that the positive effect of reducing the $\mu$-tip length can also be achieved by widening the slit channels. Based on the simulation result, we have increased the slit channel width from 50 to $150 \mu \mathrm{m}$ (increase by a factor of 3) with the $\mu$-tip length fixed to $100 \mu \mathrm{m}$. With this scheme, we successfully fabricated 200 stripes (34 stripes per inch (SPI)), as evident in Figure 11a showing the image of 200 stripes coated at $36 \mathrm{~mm} / \mathrm{s}$. To enhance the visibility of fine stripes, we thermally evaporated 50-nm-thick aluminum atop the coated stripes and captured the Al-coated side by a camera. The coated stripes are shown to be well defined. We measured the stripe profiles and presented the results in Figure 11b. The average stripe width and thickness were measured to be 82.6 and $96.5 \mathrm{~nm}$, respectively. It is observed that the 
maximum coating speed $(36 \mathrm{~mm} / \mathrm{s})$ for multiple stripe coating was even higher than that $(25 \mathrm{~mm} / \mathrm{s})$ for single stripe coating, a direct consequence of the reduced $\mu$-tip length. For high-density stripe coatings, therefore, the $\mu$-tip is preferred to be short and the slit channel is desired to be wide. If the $\mu$-tip is too short, however, the meniscus is not well controlled by the $\mu$-tip. Namely, the meniscus would be formed between the die lip and the substrate rather than between the $\mu$-tip and the substrate. In this case, the solution would spread laterally along the gap difference and thus the merging of the menisci between two adjacent stripes easily occurs, hindering an increase of stripe density. To avoid it, the $\mu$-tip length is preferably at least $50 \mu \mathrm{m}$. If the slit channels are too wide, the fluid distribution among channels would be non-uniform. Namely, more fluid might flow through the slit channels located near the inlet. This can be resolved by making the shim thin.

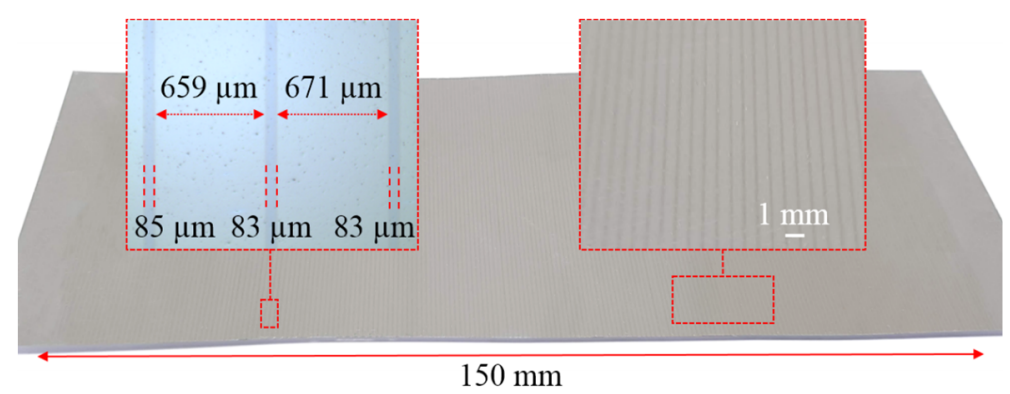

(a)

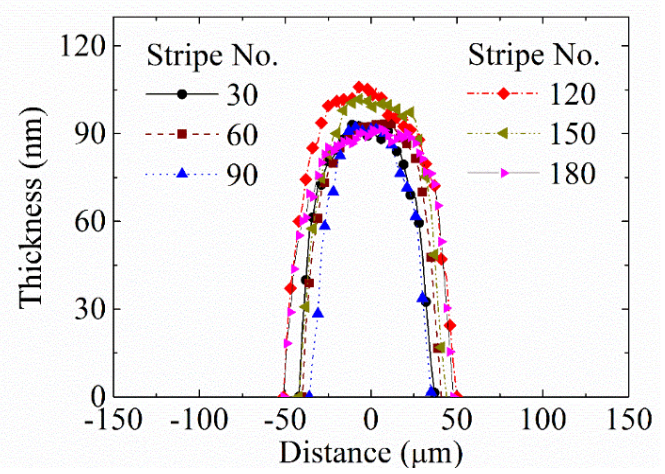

(b)

Figure 11. (a) Photo of 200 PEDOT:PSS stripes coated using $150-\mu \mathrm{m}$-wide slit channels and $100-\mu \mathrm{m}$-long $\mu$-tips at a maximum coating speed of $36 \mathrm{~mm} / \mathrm{s}$; (b) measured profiles of those stripes at different positions.

Finally, we fabricated multiple OLED stripes atop the coated stripes. To fabricate OLED devices, we need to deposit and pattern a transparent anode on the PET film roll. It is highly expensive using the commonly used indium tin oxide (ITO). Instead, we fabricated 200 conductive PEDOT:PSS (Clevios PH 1000) stripes under the same conditions as above. The conductivity of PEDOT:PSS stripes was enhanced by doping $5 \mathrm{wt}$ \% dimethyl sulfoxide (DMSO) [39]. As expected, we achieved 200 conductive stripes only with the shim with $150-\mu \mathrm{m}$-wide slit channels. The average width $(81.4 \mu \mathrm{m})$ and thickness $(97.1 \mathrm{~nm})$ of conductive PEDOT:PSS stripes were almost the same as those of stripes (Clevios AI 4083) used mainly for a hole injection layer of OLEDs. There appeared random line breakup in 10-15 $\mu$-tips when using the shim with 50- $\mu$ m-wide slit channels and in 5-8 $\mu$-tips using the reversely tapered slit channels. We also measured the width and thickness non-uniformities between stripes, which were defined as (maximum width (thickness) - minimum width (thickness))/(2 $\times$ average width (thickness)). The width non-uniformity between stripes was as low as $19.1 \%$ and the thickness non-uniformity was $13 \%$. The film uniformity would be degraded due to a misalignment between the shim and meniscus guide, which occurs when they are embedded into the slot-die head manually. Figure 12 shows the schematic fabrication flow of OLED stripes. After fabricating 200 conductive stripes, 
a contact pad was formed using the conventional slot-die head for large-area coatings (coating width of $150 \mathrm{~mm}$ ). Such patch coating was performed by shifting the slot-die head up and down. The sample was attached to a carrier glass for handling the flexible sample and then loaded into a thermal evaporator [39]. A phosphorescent green OLED was fabricated by sequentially depositing KHI-001 (Duksan Neolux, Cheonan-si, Chungcheongnam-do, Korea, $15 \mathrm{~nm}$ ) for a hole injection layer, KHT-001 (Duksan Neolux, $40 \mathrm{~nm}$ ) for a hole transport layer, 4,4'-bis (N-carbazolyl)-1,1'-biphenyl (CBP, $15 \mathrm{~nm}$ ) for an emission layer, 4,7-diphenyl-1,10-phenanthroline (Bphen, $10 \mathrm{~nm}$ ) for a hole/exciton blocking layer, LG201 (LG Chem., $30 \mathrm{~nm}$ ) for an electron transport layer, lithium fluoride (LiF, $1 \mathrm{~nm}$ ) for an electron injection layer, and aluminum $(\mathrm{Al}, 100 \mathrm{~nm})$ for cathode. For green light emission, $8 \mathrm{wt} . \%$ fac-tris (2-phenylpyridine) iridium $\left(\operatorname{Ir}(\mathrm{ppy})_{3}\right)$ was doped in the emission layer. The deposition rate was $0.5 \mathrm{~nm} / \mathrm{s}$ under a base pressure of $2 \times 10^{-6}$ Torr. Since the vacuum chamber is optimized for a $100 \mathrm{~mm}$ $\times 100 \mathrm{~mm}$ samples, we fabricated 160 OLED stripes atop the 160 PEDOT:PSS stripes. For simplicity, the OLED device was not encapsulated. Figure 13 exhibits the microscopic electroluminescent photos of OLED stripes. It is clearly seen that the striped OLEDs emit green light. The luminance from them was measured to be $325 \mathrm{~cd} / \mathrm{m}^{2}$ at a bias voltage $5 \mathrm{~V}$. Since the OLED device was exposed to air, oxidization inevitably appeared in several OLED stripes [39], causing partial non-emission. Nevertheless, we achieved well-defined striped emission.
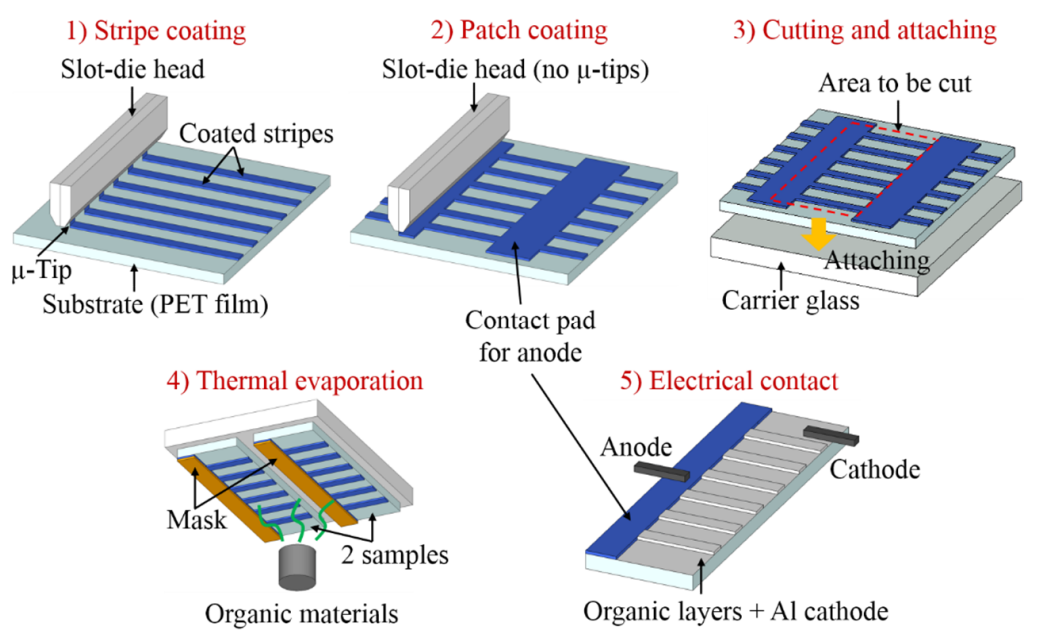

Figure 12. Schematic fabrication flow of multiple organic light-emitting diode (OLED) stripes.
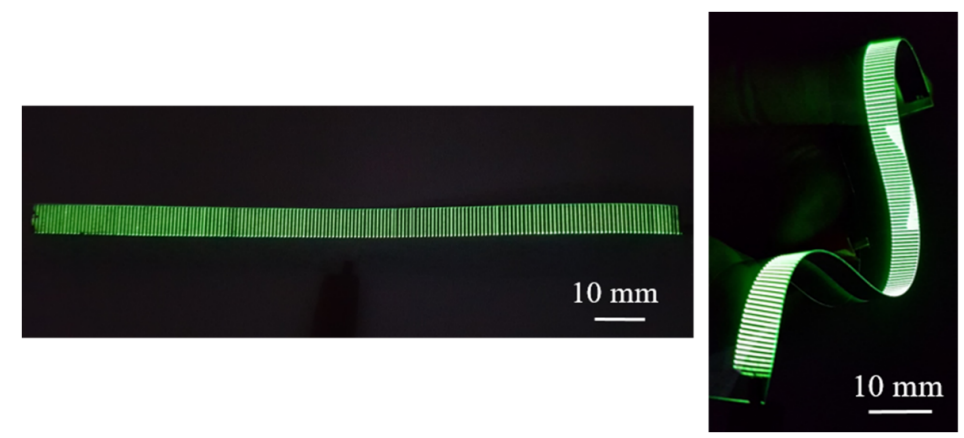

Figure 13. Microscopic electroluminescent photos of straight and curved 160 OLED stripes at $5 \mathrm{~V}$.

\section{Conclusions}

We demonstrated that the rectangular-shaped wide slit channel reduced the hydraulic resistance and supplied more fluid to the substrate. It enabled us to increase the coating velocity, causing a decrease in the width and thickness of the PEDOT:PSS stripe. Using the slit channel with a width of $150 \mu \mathrm{m}$ and the $\mu$-tip with a length of $250 \mu \mathrm{m}$, we obtained a single PEDOT:PSS stripe having a width of $90 \mu \mathrm{m}$ and a thickness of $105 \mathrm{~nm}$ at a maximum coating velocity of $25 \mathrm{~mm} / \mathrm{s}$. According to the circuit 
simulation results, we reduced the $\mu$-tip length to $100 \mu \mathrm{m}$ and fixed the slit channel width to $150 \mu \mathrm{m}$ for high-density stripe coatings. With this scheme, it was feasible to fabricate 200 PEDOT:PSS stripes with the average width of $82.6 \mu \mathrm{m}$ and thickness of $96.5 \mathrm{~nm}$ at $36 \mathrm{~mm} / \mathrm{s}$. The equivalent electrical circuit with a DC voltage source as a pressure source also captured the phenomenon; when line breakup occurred at one $\mu$-tip, the coated stripes next to it widened. Atop those PEDOT:PSS stripes, we fabricated 160 OLED stripes (34 SPI) and achieved light emission from them with the luminance of $325 \mathrm{~cd} / \mathrm{m}^{2}$ at $5 \mathrm{~V}$. For potential applications in large-area OLEDs, more research on the feasibility of fine stripe coating using non-aqueous (organic) solvents with varying viscosity, surface tension, and wettability on an underlying layer is needed.

Author Contributions: Slot die coating and measurement, D.S. and J.L.; data analysis, writing, supervision, J.P. All authors have read and agreed to the published version of the manuscript.

Funding: This paper was partially supported by the Post-doctoral Program of KOREATECH and Basic Science Research Program through the National Research Foundation of Korea (NRF) (NRF-2018R1D1A1B07042248) funded by the Ministry of Education.

Conflicts of Interest: The authors declare no conflict of interest.

\section{References}

1. Zhou, L.; Yang, L.; Yu, M.; Jiang, Y.; Liu, C.; Lai, W.; Huang, W. Inkjet-printed small-molecule organic light-emitting diodes: Halogen-free inks, printing optimization, and large-area patterning. ACS Appl. Mater. Interfaces 2017, 9, 40533-40540. [CrossRef] [PubMed]

2. Ha, T.W.; Kim, Y.B.; Heo, G.S.; Hwang, I.; Jeon, H.G.; Park, B. Organic light-emitting devices based on solution-processable small molecular emissive layers doped with interface-engineering additives. RSC Adv. 2016, 6, 33063. [CrossRef]

3. Dubey, D.K.; Sahoo, S.; Wang, C.W.; Jou, J.-H. Solution process feasible highly efficient white organic light emitting diode. Org. Electron. 2019, 69, 232-240. [CrossRef]

4. Chen, Y.; Wang, J.; Zhong, Z.; Jiang, Z.; Song, C.; Hu, Z.; Peng, J.; Wang, J.; Gao, Y. Fabricating large-area white OLED lighting panels via dip-coating. Org. Electron. 2016, 37, 458-464. [CrossRef]

5. Morales-Masis, M.; Dauzou, F.; Jeangros, Q.; Dabirian, A.; Lifka, H.; Gierth, R.; Ruske, M.; Moet, D.; Hessler-Wyser, A.; Ballif, C. An indium-free anode for large-area flexible OLEDs: Defect-free transparent conductive zinc tin oxide. Adv. Funct. Mater. 2016, 26, 384-392. [CrossRef]

6. Gu, X.; Zhou, Y.; Kevin, G.; Kurosawa, T.; Gun, Y.; Li, Y.; Lin, H.; Schroeder, B.C.; Yan, H.; Molina-Lopez, F.; et al. Roll-to-roll printed large-area all-polymer solar cells with $5 \%$ efficiency based on a low crystallinity conjugated polymer blend. Adv. Energy Mater. 2017, 7, 1602742. [CrossRef]

7. Chern, Y.-C.; Wu, H.-R.; Chen, Y.-C.; Zan, H.-W.; Meng, H.-F.; Horng, S.-F. Reliable solution processed planar perovskite hybrid solar cells with large-area uniformity by chloroform soaking and spin rinsing induced surface precipitation. AIP Adv. 2015, 5, 087125. [CrossRef]

8. Wang, T.; Zhang, Y.; Liu, Q.; Cheng, W.; Wang, X.; Pan, L.; Xu, B.; Xu, H. A self-healable, highly stretchable, and solution processable conductive polymer composite for ultrasensitive strain and pressure sensing. Adv. Funct. Mater. 2018, 28, 1705551. [CrossRef]

9. Khim, D.; Ryu, G.S.; Park, W.T.; Kim, H.; Lee, M.; Noh, Y. Precisely controlled ultrathin conjugated polymer films for large area transparent transistors and highly sensitive chemical sensors. Adv. Mater. 2016, 28, 2752-2759. [CrossRef]

10. Liu, Y.; Elzatahry, A.A.; Luo, W.; Lan, K.; Zhang, P.; Fan, J.; Wei, Y.; Wang, C.; Deng, Y.; Zheng, G.; et al. Surfactant-templating strategy for ultrathin mesoporous $\mathrm{TiO}_{2}$ coating on flexible graphitized carbon supports for high-performance lithium-ion battery. Nano Energy 2016, 25, 80-90. [CrossRef]

11. He, J.; Bao, K.; Cui, W.; Yu, J.; Huang, C.; Shen, X.; Cui, Z.; Wang, N. Construction of large-area uniform graphdiyne film for high-performance lithium-ion batteries. Chem. Eur. J. 2018, 24, 1187-1192. [CrossRef] [PubMed]

12. Zheng, X.; Liu, Y.; Zhu, Y.; Ma, F.; Feng, C.; Yu, Y.; Hu, H.; Li, F. Efficient inkjet-printed blue OLED with boosted charge transport using host doping for application in pixelated display. Opt. Mater. 2020, 101, 109755. [CrossRef] 
13. Hu, Z.; Yin, Y.; Ali, M.U.; Peng, W.; Zhang, S.; Li, D.; Zou, T.; Li, Y.; Jiao, S.; Chen, S.; et al. Inkjet printed uniform quantum dots as color conversion layers for full-color OLED displays. Nanoscale 2020, 12, 2103-2110. [CrossRef]

14. Merklein, L.; Daume, D.; Braig, F.; Schlisske, S.; Rödlmeier, T.; Mink, M.; Kourkoulos, D.; Ulber, B.; Biase, M.D.; Meerholz, K.; et al. Comparative study of printed multilayer OLED fabrication through slot die coating, gravure and inkjet printing, and their combination. Colloids Interfaces 2019, 3, 32. [CrossRef]

15. Smarsly, E.; Daume, D.; Tone, R.; Veith, L.; Curticean, E.R.; Wacker, I.; Schröder, R.R.; Sauer, H.M.; Dörsam, E.; Bunz, U.H.F. Printing poly (p-phenyleneethynylene) PLEDs. ACS Appl. Mater. Interfaces 2019, 11, 3317-3322. [CrossRef] [PubMed]

16. Lee, Y.G.; Lee, D.J.; Bae, J.H.; Lee, J.Y.; Jung, B.J.; Lee, J. Investigation of nozzle printing parameters for OLED emitting layers. Mol. Cryst. Liq. Cryst. 2018, 660, 17-23. [CrossRef]

17. Yoon, D.G.; Kang, M.G.; Kim, J.B.; Kang, K. Nozzle printed-PEDOT: PSS for organic light emitting diodes with various dilution rates of ethanol. Appl. Sci. 2018, 8, 203. [CrossRef]

18. Staat, H.J.; van der Bos, A.; van den Berg, M.; Reinten, H.; Wijshoff, H.; Versluis, M.; Lohse, D. Ultrafast imaging method to measure surface tension and viscosity of inkjet-printed droplets in flight. Exp. Fluids 2017, 58, 2. [CrossRef]

19. Razza, S.; Di Giacomo, F.; Matteocci, F.; CinÓ, L.; Palma, A.L.; Casaluci, S.; Cameron, P.; D’Epifanio, A.; Licoccia, S.; Reale, A.; et al. Perovskite solar cells and large area modules $\left(100 \mathrm{~cm}^{2}\right)$ based on an air flow-assisted PbI2 blade coating deposition process. J. Power Sources 2015, 277, 286-291. [CrossRef]

20. Seok, J.Y.; Yang, M. A novel blade-jet coating method for achieving ultrathin, uniform film toward all-solution-processed large-area organic light-emitting diodes. Adv. Mater. Technol. 2016, 1, 1600029. [CrossRef]

21. Cang, Y.-F.; Yang, L.-S.; Su, H.-T.; Liao, S.-Y.; Niu, M.-C.; Mahesh, K.P.O.; Chen, C.-H.; Chao, Y.-C.; Meng, H.-F.M.; Huang, H.-L.; et al. All-solution-processed red and orange-red organic light-emitting diodes with high-efficiencies: The effect of mixed-host emissive layers and thermal annealing treatment. ChemPlusChem 2019, 84, 1375-1383. [CrossRef]

22. Park, B.; Kwon, O.E.; Yun, S.H.; Jeon, H.G.; Huh, Y.H. Organic semiconducting layers fabricated by selfmetered slot-die coating for solution-processable organic light-emitting devices. J. Mater. Chem. C 2014, 2 , 8614-8621. [CrossRef]

23. Griffin, J.; Ryan, A.J.; Lidzey, D.G. Solution modification of PEDOT: PSS inks for ultrasonic spray coating. Org. Electron. 2017, 41, 245-250. [CrossRef]

24. Koutsiaki, C.; Kaimakamis, T.; Zachariadis, A.; Papamichail, A.; Kamaraki, C.; Fachouri, S.; Gravalids, C.; Laskarakis, A.; Logothetidis, S. Efficient combination of roll-to-roll compatible techniques towards the large area deposition of a polymer dielectric film and the solution-processing of an organic semiconductor for the field-effect transistors fabrication on plastic substrate. Org. Electron. 2019, 73, 231-239. [CrossRef]

25. Han, D.; Yasser, K.; Karthik, G.; Adrien, P.; Ana, C.A. Emission area patterning of organic light-emitting diodes (OLEDs) via printed dielectrics. Adv. Funct. Mater. 2018, 28, 1802986. [CrossRef]

26. Mohamad, D.K.; Griffin, J.; Bracher, C.; Barrows, A.T.; Lidzey, D.G. Spray-cast multilayer organometal perovskite solar cells fabricated in air. Adv. Energy Mater. 2016, 6, 1600994. [CrossRef]

27. Lin, C.F.; Wong, D.S.; Liu, T.; Wu, P. Operating windows of slot die coating: Comparison of theoretical predictions with experimental observations. Adv. Polym. Technol. 2010, 29, 31-44. [CrossRef]

28. Carvalho, M.S.; Kheshgi, H.S. Low-flow limit in slot coating: Theory and experiments. AlChE J. 2000, 46, 1907-1917. [CrossRef]

29. Larsen-Olsen, T.T.; Andreasen, B.; Andersen, T.R.; Böttiger, A.P.L.; Bundgaard, E.; Norrman, K.; Andreasen, J.W.; Jørgensen, M.; Krebs, F.C. Simultaneous multilayer formation of the polymer solar cell stack using roll-to-roll double slot-die coating from water. Sol. Energy Mater. Sol. Cells 2012, 97, 22-27. [CrossRef]

30. Kang, H.; Park, J.; Shin, K. Statistic analysis for the manufacturing of multi-strip patterns by roll-to-roll single slot-die systems. Robot. Comput. Integr. Manuf. 2014, 30, 363-368. [CrossRef]

31. Abbel, R.; de Vries, I.; Langen, A.; Kirchner, G.; t’Mnnetje, H.; Gorter, H.; Wilson, J. Toward high volume solution based roll-to-roll processing of OLEDs. J. Mater. Res. 2017, 32, 2219-2229. [CrossRef]

32. Liu, H.; Xu, W.; Tan, W.; Zhu, X.; Wang, J.; Peng, J.; Cao, Y. Line printing solution-processable small molecules with uniform surface profile via ink-jet printer. J. Colloid Interface Sci. 2016, 465, 106-111. [CrossRef] [PubMed] 
33. Singh, M.; Haverinen, H.M.; Dhagat, P.; Jabbour, G.E. Inkjet printing-process and its applications. Adv. Mater. 2010, 22, 673-685. [CrossRef] [PubMed]

34. Soltman, D.; Subramanian, V. Inkjet-printed line morphologies and temperature control of the coffee ring effect. Langmuir 2008, 24, 2224-2231. [CrossRef]

35. Han, D.H.; Lee, S.H.; Ahn, W.; Nam, J.; Jung, H.W. Effect of shim configuration on flow dynamics and operability windows in stripe slot coating process. J. Coat. Technol. Res. 2014, 11, 19-29. [CrossRef]

36. Krebs, F.C. Polymer solar cell modules prepared using roll-to-roll methods: Knife-over-edge coating, slot-die coating and screen printing. Sol. Energy Mater. Sol. Cells 2009, 93, 465-475. [CrossRef]

37. Liu, K.; Larsen-Olsen, T.T.; Lin, Y.; Beliatis, M.; Bundgaard, E.; Jørgensen, M.; Krebs, F.C.; Zhan, X. Roll-coating fabrication of flexible organic solar cells: Comparison of fullerene and fullerene-free systems. J. Mater. Chem. A 2016, 4, 1044-1051. [CrossRef]

38. Verma, A.; Martineau, D.; Hack, E.; Makha, M.; Turner, E.; Nüesch, F.; Heier, J. Towards industrialization of perovskite solar cells using slot die coating. J. Mater. Chem. C 2020, 8, 6124-6135. [CrossRef]

39. Kim, G.; Lee, J.; Shin, D.; Park, J. Roll-to-roll fabrication of PEDOT: PSS Stripes using slot-die head with $\mu$-tips for AMOLEDs. IEEE Trans. Electron. Devices 2019, 66, 1041-1049. [CrossRef]

40. Kim, G.E.; Shin, D.K.; Lee, J.Y.; Park, J.W. Effect of surface morphology of slot-die heads on roll-to-roll coatings of fine PEDOT: PSS stripes. Org. Electron. 2019, 66, 116-125. [CrossRef]

41. Lee, J.; Park, J. Increased stripe density of slot-coated PEDOT: PSS using a meniscus guide with linearly tapered $\mu$-tips for OLEDs. Org. Electron. 2020, 83, 105772. [CrossRef]

42. Lun, I.; Calay, R.K.; Holdo, A.E. Modelling two-phase flows using CFD. Appl. Energy 1996, 53, $299-314$. [CrossRef]

43. Sartor, L. Slot Coating: Fluid Mechanics and Die Design. Ph.D. Thesis, University of Minnesota, Saint Paul, MN, USA, 1990.

44. Bhamidipati, K.L.; Didari, S.; Bedell, P.; Harris, T.A.L. Wtting phenomena during processing of high-viscosity shear-thinning fluid. J. Non Newton. Fluid Mech. 2011, 166, 723-733. [CrossRef]

45. Bhamidipati, K.L.; Didari, S.; Harris, T.A.L. Experimental study on air entrainment in slot die coating of high-viscosity, shear-thinning solutions. Chem. Eng. Sci. 2012, 80, 195-204. [CrossRef]

46. Nam, J.; Scriven, L.E.; Carvalho, M.S. Tracking birth of vortex in flows. J. Comput. Phys. 2009, 228, 4549-4567. [CrossRef]

47. Oh, K.W.; Lee, K.; Ahn, B.; Furlani, E.P. Design of pressure-driven microfluidic networks using electric circuit analogy. Lab Chip 2012, 12, 515-545. [CrossRef]

48. Lee, K.; Kim, C.; Ahn, B.; Panchapakesan, R.; Full, A.R.; Nordee, L.; Kang, J.Y.; Oh, K.W. Generalized serial dilution module for monotonic and arbitrary microfluidic gradient generators. Lab Chip 2009, 9, 709-717. [CrossRef]

49. Ahmad, N.A.; Bahry, S.I.S.; Ali, Z.M.; Daud, A.M.M.; Musa, S. Effect of flow resistance in open rectangular channel. MATEC Web Conf. 2017, 97, 01107. [CrossRef]

50. Angelescu, D.E. Highly Integrated Microfluidics Design; Artech House: Boston, MA, USA, 2011.

51. Mortensen, N.A.; Okkels, F.; Bruus, H. Reexamination of Hagen-Poiseuille flow: Shape dependence of the hydraulic resistance in microchannels. Phys. Rev. E 2005, 71, 057301. [CrossRef]

(C) 2020 by the authors. Licensee MDPI, Basel, Switzerland. This article is an open access article distributed under the terms and conditions of the Creative Commons Attribution (CC BY) license (http://creativecommons.org/licenses/by/4.0/). 